\title{
Small scale gas turbine combustor sizing
}

JEL: L97 DOI: 10.24136/atest.2019.032

Data zgłoszenia: 15.12.2018 Data akceptacji: 08.02.2019

Prezentowany artykuł dotyczy projektowania wstępnego komór spalania silników turbinowych klasy mikro. W odróżnieniu od metodyki projektowania komór spalania dużych komercyjnych silników turbinowych, ich mniejsze odpowiedniki należą do konstrukcji eksperymentalnych. Aby dokonać próby budowy na miare uniwersalnego modelu obliczeniowego należy zbudować bazę wiedzy która pozwoli na jasne wyznaczenie warunków brzegowych dla przyszłych badań. Niewątpliwą zaletą wzorowania się na istniejących rozwiązaniach jest możliwość szybkiego uzyskania prototypowego rozwiązania, bez konieczności głębszego wnikania w skomplikowany mechanizm spalania paliwa w komorach o małej objętości.

Słowa kluczowe: silniki turbinowe, mikro, komora spalania, projektowanie wstępne.

Wstęp

Turbinowe silniki odrzutowe klasy mikro charakteryzują się uproszczoną konstrukcją w porównaniu do silników stosowanych jako źródło napędu samolotów. Powszechnie stosowany jest układ konstrukcyjny (1R-1T) - gdzie zespół wirnikowy składa się z: wirnika sprężarki promieniowej, wału pędni oraz wirnika turbiny osiowej (rys.1). Jednym z dylematów zwiazanym z projektowaniem nowych silników turbinowych tej klasy jest trudność z pozyskaniem wiarygodnej bazy informacji która umożliwi wzorowanie się na sprawdzonych rozwiazaniach - obniżając ryzyko niepowodzenia projektu.

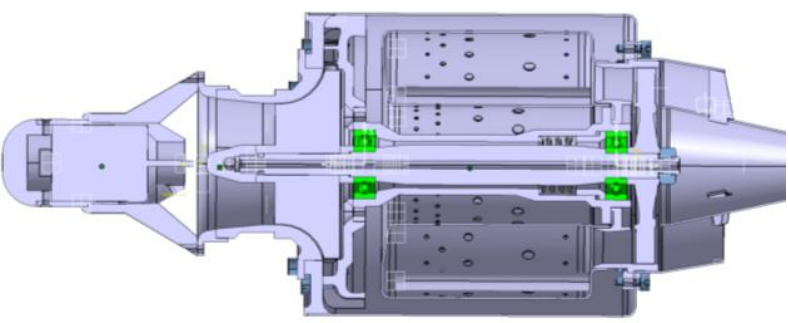

Rys. 1. Turbinowy silnik odrzutowy klasy mikro.

Możliwe jest w procesie projektowania wspomaganie się nowoczesnymi środowiskami obliczeniowymi w szczególności CFD (komputerową analizą zjawisk przepływowych). Aby uzyskane wyniki symulacji numerycznej można było uznać za wiarygodne, konieczne jest przeprowadzenie procesu walidacji przyjętej metodyki prowadzenia obliczeń na istniejącym rozwiazaniu technicznym. Istotna przeszkoda jest zastrzeżenie patentowe rozwiązania konstrukcyjnego $[2,3,4]$ co uniemożliwia wykorzystanie geometrii uzyskanej na drodze inżynierii odwrotnej. Bardzo często uproszczeniem które prowadzi do uzyskania błędnych wyników jest rozpatrywanie elementów komory spalania jako oddzielnego modułu silnika z pominięciem zespołu sprężarki zakładając parametry średnie na wylocie z dyfuzora sprężarki. Kolejnym błędnym założeniem jest wykonanie symulacji traktujących domenę przepływowa jako zjawisko dwuwymiarowe (kierunek osiowy i promieniowy).Symulacja dwuwymiarowa obarczona jest błędem wynikającym z pominięcia zmiennej składowej obwodowej, która powoduje przemieszczenie pola temperatury względem składowej obwodowej (rys.2). Pozostaje zadać sobie pytanie, w jaki możliwie prosty sposób rozwiazać problem aby wygenerowane rozwiązanie umożliwiło funkcjonowanie silnika a nie stanowiło zbioru błędnych założeń projektowych.

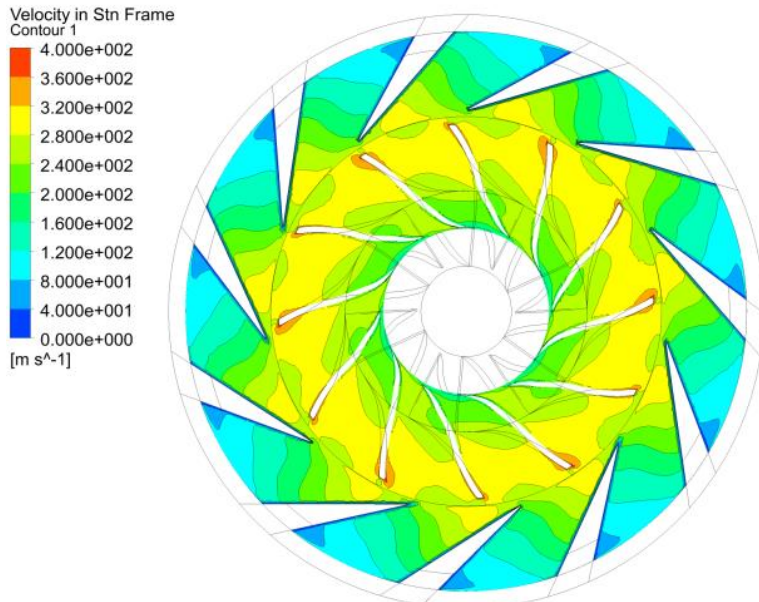

Rys. 2. Przykładowa symulacja stopnia promieniowego sprężarki rozkład prędkości [1].

\section{Zasoby literaturowe}

W zakresie literatury dotyczącej projektowania silników klasy mikro problem skalowania elementów rury żarowej podjał T. Kamps [2]. Z jego rozważań wynika że w przypadku wymiarów zewnętrznych główna rekomendacja jest stosowanie podobieństwa geometrycznego. Natomiast w kwestii skalowania otworów chłodzenia i mieszania strumieni obiegu pierwotnego i wtórnego stosuje zależność :

$$
f=\sqrt{3030 \cdot d_{2} \cdot h}
$$

Powyższa zależność obowiazuje dla wirników sprężarek o kanale krzywoliniowym. Dla wirników sprężarki o kanale prostym zależność zmodyfikowano do postaci :

$$
f=\sqrt{2600 \cdot d_{2} \cdot h}
$$

Zmiennymi sa odpowiednio średnica zewnętrzna wirnika $d_{2}$ oraz wysokość kanału przepływowego na wylocie $z$ wirnika $-h$. Autor nie wspomina 0 innych liczbach kryterialnych które umożliwiłyby precyzyjniejsze obliczenia. Przyjmuje on jeden schemat rozwiazania dystrybucji otworów w pierścieniach rury żarowej [2]. Głównym pytaniem nurtującym autora artykułu jest - jak w świetle przedstawionego rozwiązania konstrukcyjnego prezentują się konkurencyjne rozwiazania ? Zidentyfikowano grupę siedmiu reprezentatywnych silników turbinowych celem przeanalizowania stosowanych rozwiazań konstrukcyjnych rury żarowej. 


\section{Rura żarowa mikrosilnika turbinowego}

Kluczowym elementem komory spalania mikrosilnika turbinowego jest rura żarowa. Jest ona odpowiedzialna za przeprowadzenie procesu spalania mieszanki paliwowo - powietrznej. Składa się ona z następujących elementów : denka(1), pierścienia zewnętrznego(2) i wewnętrznego(3) oraz pierścienia tylnego z parownicami $(4,5)$ który ustala położenie rury żarowej w silniku (rys.3). Mechanizm zasilania paliwem opiera się na procesie odparowania paliwa w parownicach o przepływie zwrotnym o kierunku przeciwnym do przepływu czynnika roboczego przez kanał silnika. Zastosowanie powyższego rozwiazzania wynika z jego uproszczonej konstrukcji oraz wysokiej niezawodności.

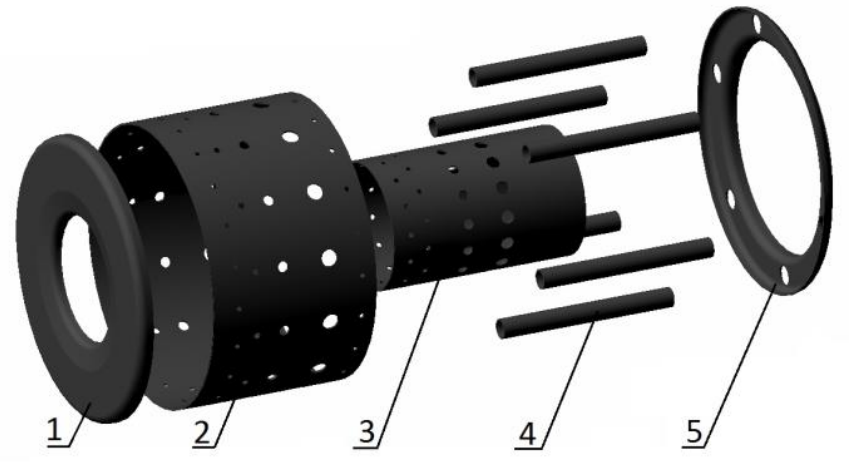

Rys. 3. Rura żarowa silnika turbinowego klasy mikro.

Analizujac budowę rury żarowej za istotne wymiary uznano : $L_{c}$ - długość całkowita rury żarowej, $D_{c e}$ - średnicę zewnętrzną rury żarowej, $D_{c i}$ - średnicę wewnętrzną rury żarowej (rys.4).

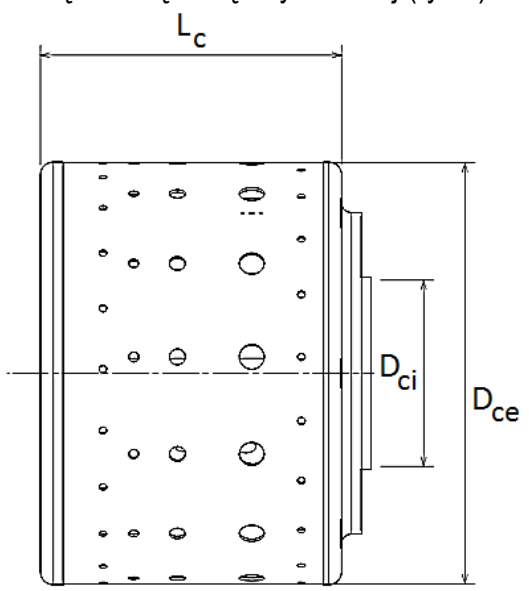

Rys. 4. Wymiary charakterystyczne dla rury żarowej.

Zebrane dane dla reprezentatywnej grupy silników przedstawiono w tabeli nr 1 [2,3,4,6,7,8,9].

Tab. 1. Reprezentatywna grupa silników turbinowych klasy mikro.

\begin{tabular}{|l|l|l|l|l|l|}
\hline \hline $\begin{array}{l}\text { Typ } \\
\text { silnika }\end{array}$ & $\begin{array}{l}\mathrm{D}_{\mathrm{ce}} \\
{[\mathrm{mm}]}\end{array}$ & $\begin{array}{l}\mathrm{D}_{\mathrm{ci}} \\
{[\mathrm{mm}]}\end{array}$ & $\begin{array}{l}\mathrm{L}_{\mathrm{c}} \\
{[\mathrm{mm}]}\end{array}$ & $\mathrm{V}\left[\mathrm{cm}^{3}\right]$ & Typ łożyska \\
\hline, $70 "$ & 70,6 & 33,1 & 52 & 635 & 688 \\
\hline MW54 & 75,7 & 32,4 & 48 & 705,7 & 688 \\
\hline OH7 & 83,6 & 38,6 & 58 & 1001,7 & 608 \\
\hline TK50 & 82 & 36 & 66 & 1125,26 & 688 \\
\hline KJ66 & 95,8 & 43,9 & 72 & 1639,7 & 608 \\
\hline GR130 & 95,5 & 41,7 & 75 & 1738,86 & 608 \\
\hline GR180 & 95,5 & 41,7 & 75 & 1738,86 & 608 \\
\hline
\end{tabular}

Rury żarowe reprezentatywnej grupy silników turbinowych klasy mikro charakteryzują się objętością V w przedziale $635-1738 \mathrm{~cm} 3$. Dodatkowe dwa parametry charakteryzujace rozmieszczenie otwo- rów w płaszczu komory spalania - spacing - liczba otworów / rozstaw otworów, dimensioning - wymiar od czoła do kolejnych rzędów otworów pierścienia (rys.5). Tworzą one unikalny wzór charakterystyczny dla danego rozwiazania konstrukcyjnego .

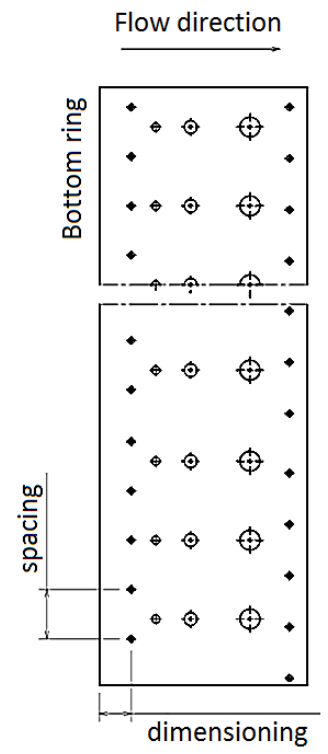

Rys. 5. Wymiary charakterystyczne pierścienia rury żarowej.

Tab. 2. Rozmieszczenie otworów w pierścieniach rury żarowej.

\begin{tabular}{|c|c|c|c|c|c|c|c|}
\hline \multirow{3}{*}{$\begin{array}{l}\text { ్ㅠ } \\
\mathbb{N}\end{array}$} & \multicolumn{7}{|c|}{ Silnik } \\
\hline & "70" & $\begin{array}{l}\text { MW } \\
54\end{array}$ & $\mathrm{OH} 7$ & $\begin{array}{l}\text { TK } \\
50\end{array}$ & KJ-66 & $\begin{array}{l}\text { GR } \\
130\end{array}$ & $\begin{array}{l}\text { GR } \\
180\end{array}$ \\
\hline & \multicolumn{7}{|c|}{ Pierścień zewnętrzny rury żarowej } \\
\hline 1 & $\begin{array}{l}24 x \\
1,4\end{array}$ & $\begin{array}{l}6 \\
\times 3,8\end{array}$ & $\begin{array}{l}12 x \\
3\end{array}$ & $\begin{array}{l}12 x \\
3\end{array}$ & $\begin{array}{l}6 x \\
4,5\end{array}$ & $\begin{array}{l}36 x \\
2\end{array}$ & $\begin{array}{l}36 x \\
2\end{array}$ \\
\hline 2 & $\begin{array}{l}12 x \\
2\end{array}$ & $\begin{array}{l}24 x \\
1,5\end{array}$ & $\begin{array}{l}24 x \\
1,5\end{array}$ & $\begin{array}{l}24 x \\
1,5\end{array}$ & $\begin{array}{l}24 x \\
1,5\end{array}$ & $\begin{array}{l}12 x \\
3,5\end{array}$ & $\begin{array}{l}12 x \\
3,5\end{array}$ \\
\hline 3 & $\begin{array}{l}24 x \\
2,8\end{array}$ & $\begin{array}{l}12 x \\
2,3\end{array}$ & $\begin{array}{l}12 x \\
2,5\end{array}$ & $\begin{array}{l}12 x \\
2,5\end{array}$ & $\begin{array}{l}12 x \\
3\end{array}$ & $\begin{array}{l}12 x \\
3,5\end{array}$ & $\begin{array}{l}12 x \\
3,2\end{array}$ \\
\hline 4 & $\begin{array}{l}12 x \\
3,9\end{array}$ & $\begin{array}{l}12 x \\
4,9 \\
\end{array}$ & $\begin{array}{l}12 x \\
3,5\end{array}$ & $\begin{array}{l}12 x \\
3,5\end{array}$ & $\begin{array}{l}24 x \\
4 \\
\end{array}$ & $\begin{array}{l}12 x \\
3,5\end{array}$ & $\begin{array}{l}12 x \\
4\end{array}$ \\
\hline 5 & $\begin{array}{l}48 x \\
1,4\end{array}$ & $\begin{array}{l}24 x \\
1,5\end{array}$ & $\begin{array}{l}48 x \\
1,5\end{array}$ & $\begin{array}{l}48 x \\
1,5\end{array}$ & $\begin{array}{l}12 x \\
6\end{array}$ & $\begin{array}{l}12 x \\
3,5\end{array}$ & $\begin{array}{l}12 x \\
3,5\end{array}$ \\
\hline 6 & & & & & & $\begin{array}{l}24 x \\
5\end{array}$ & $\begin{array}{l}24 x \\
5\end{array}$ \\
\hline 7 & & & & & & $24 \times 2$ & $\begin{array}{l}24 x \\
2\end{array}$ \\
\hline & \multicolumn{7}{|c|}{ Pierścień wewnętrzny rury żarowej } \\
\hline 1 & $\begin{array}{l}24 x \\
1,45\end{array}$ & $\begin{array}{l}24 x \\
1,5\end{array}$ & $\begin{array}{l}24 x \\
1,5\end{array}$ & $\begin{array}{l}24 x \\
1,5\end{array}$ & $\begin{array}{l}24 x \\
1,5\end{array}$ & $\begin{array}{l}24 x \\
2\end{array}$ & $\begin{array}{l}24 x \\
2\end{array}$ \\
\hline 2 & $\begin{array}{l}24 x \\
1,45\end{array}$ & $\begin{array}{l}24 x \\
1,7\end{array}$ & $\begin{array}{l}24 x \\
1,5\end{array}$ & $\begin{array}{l}24 x \\
1,5 \\
\end{array}$ & $\begin{array}{l}24 x \\
2 \\
\end{array}$ & $\begin{array}{l}12 x \\
2,5\end{array}$ & $\begin{array}{l}12 x \\
2,5 \\
\end{array}$ \\
\hline 3 & $\begin{array}{l}12 x \\
2,9\end{array}$ & $\begin{array}{l}12 x \\
2,8\end{array}$ & $\begin{array}{l}12 x \\
2,5\end{array}$ & $\begin{array}{l}12 x \\
2,5 \\
\end{array}$ & $\begin{array}{l}12 x \\
3,5\end{array}$ & $\begin{array}{l}12 x \\
3 \\
\end{array}$ & $\begin{array}{l}12 x \\
3 \\
\end{array}$ \\
\hline 4 & $12 \times 4$ & $\begin{array}{l}12 x \\
4,9\end{array}$ & $\begin{array}{l}12 x \\
3,5\end{array}$ & $\begin{array}{l}12 x \\
3,5\end{array}$ & $12 \times 6$ & $\begin{array}{l}12 x \\
3\end{array}$ & $\begin{array}{l}12 x \\
3\end{array}$ \\
\hline 5 & & $\begin{array}{l}12 x \\
1,5\end{array}$ & $\begin{array}{l}12 x \\
3,5\end{array}$ & $\begin{array}{l}12 x \\
3,5\end{array}$ & & $\begin{array}{l}12 x \\
3\end{array}$ & $\begin{array}{l}12 x \\
3\end{array}$ \\
\hline 6 & & & $\begin{array}{l}24 x \\
1,5\end{array}$ & $12 \times 2$ & & $\begin{array}{l}12 x \\
5,5\end{array}$ & $\begin{array}{l}12 x \\
5,5\end{array}$ \\
\hline$L_{w}$ & 1,393 & 1,063 & 1,288 & 1,434 & 1,349 & 1,39 & 1,39 \\
\hline
\end{tabular}

Sposób rozmieszczenia otworów w pierścieniach rury żarowej ujęto w tabeli nr $2[2,3,4,6,7,8,9]$. Dodatkowo wprowadzono współczynnik określający długość względną rury żarowej :

$$
L_{w}=\frac{\left(D_{c e}-D_{c i}\right)}{L_{c}}
$$


Pozwala on w prosty sposób uchwycić proporcję pomiędzy wymiarami denka a długością komory spalania.

Istotnym parametrem z punktu widzenia oceny rozwiąania jest sumaryczna powierzchnia rozmieszczenia otworów odniesiona do pola powierzchni denka co pozwala na łatwiejsze przyswojenie proporcji która w sposób pośredni informuje o intensywności wprowadzenia powietrza do przekroju rury żarowej na kierunku promieniowym. Im większa wartość współczynnika tym intensywniejsze wprowadzanie powietrza do przekroju rury żarowej

$$
\bar{A}=\frac{1}{A_{D}} \sum_{i=1}^{n} A_{i}
$$

gdzie :

$A_{D}$ - pole przekroju denka komory spalania,

$A_{i}$ - sumaryczne pole przekroju otworów rury żarowej na kierunku osiowym,

$i$ - nr kolejnego rzędu otworów pierścienia rury,

$n$ - liczba rzędów otworów w rurze.

Celowo zrezygnowano z podawania masowego natężenia przepływu przez otwory, gdyż parametr ten zależy od: zakresu pracy silnika składowych osiowych, promieniowych i obwodowych, które uznano za niewiadome.

\section{Przegląd dystrybucji powietrza w wybranych rurach} żarowych

Pierwsze dwa rozwiazzania dotyczą silników wyposażonych w łożyska typu 688.

Wymiary wewnętrzne komory spalania „70" wskazują trzy obszary o różnej intensywności procesu spalania (rys.6). Pierwszy do 0,2 długości względnej Lc gdzie następuje wstępne odparowanie paliwa i inicjalizajca procesów spalania, Drugi do długości $0,8 L_{c}$ gdzie następuje intensyfikacja procesów spalania i strefę trzecia gdzie intensywnie schładzane są spaliny przed wieńcem dyszowym turbiny.

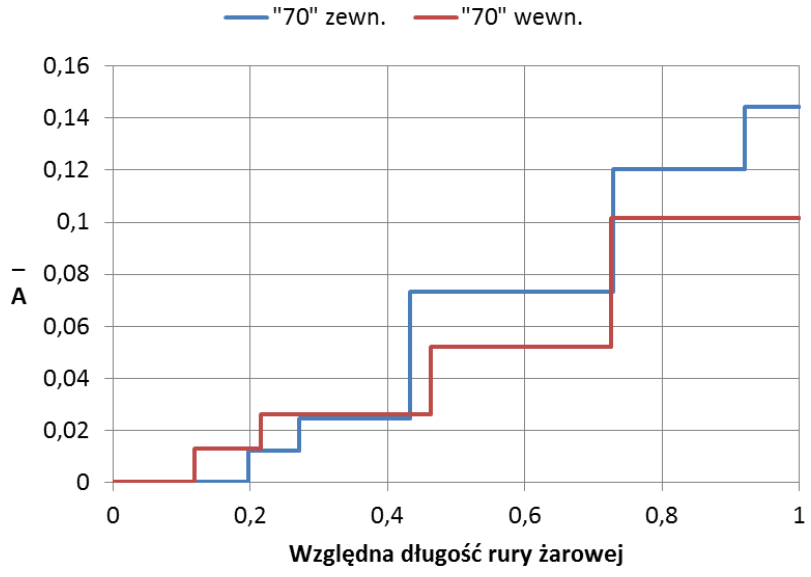

Rys. 6. Wymiary charakterystyczne dla rury żarowej „70”.

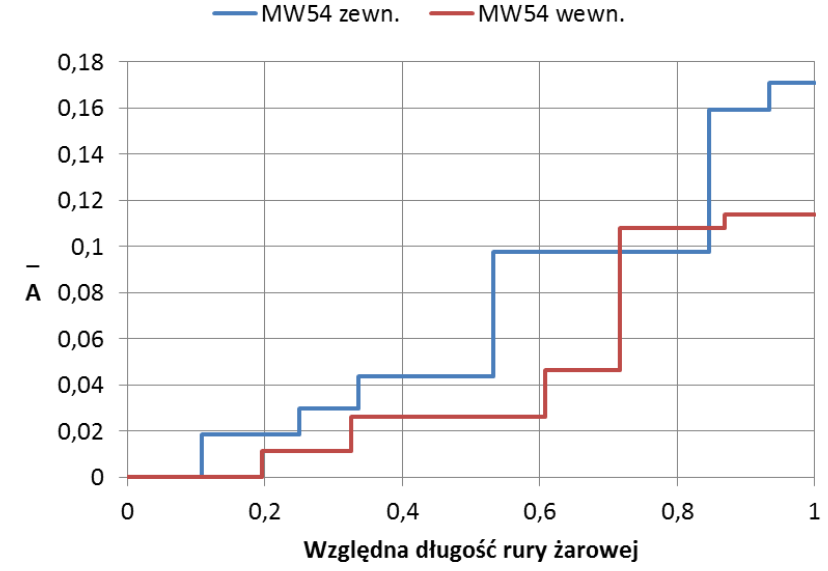

Rys. 7. Wymiary charakterystyczne dla rury żarowej MW54 [8]

W przypadku silnika MW54 mamy do czynienia z komora kompaktową o współczynniku $L_{w}=1,04$ (rys.7). Konsekwencja skrócenia długości rury żarowej jest wydłużenie strefy inicjalizacji procesów spalania aż do 0,35 względnej długości rury żarowej. Podobnie jak w przypadku komory „70" większą średnicą otworów charakteryzuja się pierścienie zewnętrzne i one są w głównej mierze odpowiedzialne ze procesy cieplne wewnatrz rury żarowej.

Komora spalania silników TK-50/ OH7 charakteryzuje się odmiennym podziałem powierzchni otworów rury żarowej (rys.8).

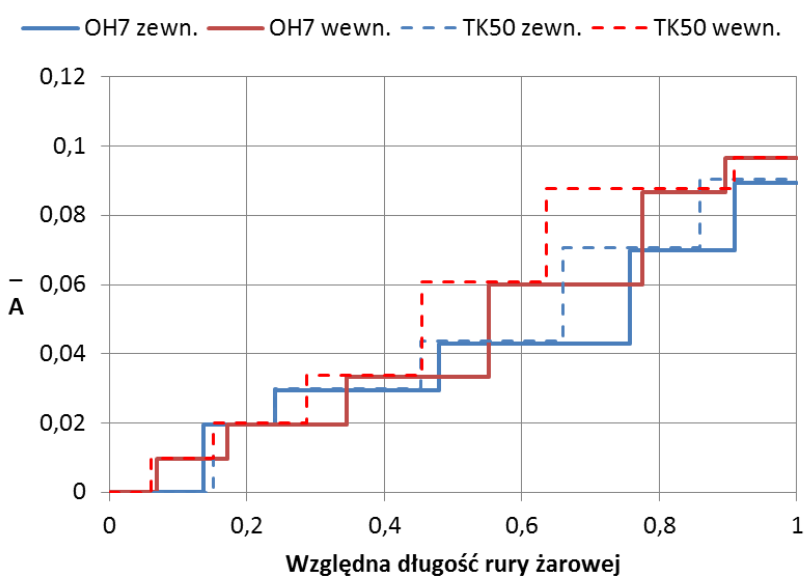

Rys. 8. Wymiary charakterystyczne dla rury żarowej silników TK-50 i OH7 [3,4]

Istotny jest w porównaniu do silników prezentowanych wcześniej symetryczny udział $w$ procesach wprowadzania powietrza wewnątrz rury pierścieni zewnętrznych i wewnętrznych.

Pozostałe rozwiązania dotyczą komór spalania dla pędni zbudowanych na łożyskach 608. Pierwszym rozwiazaniem jest komora spalania silnika KJ-66 (rys.9). W porównaniu do komór spalania „70" i MW54 jest ona rozwiąaniem pośrednim. 


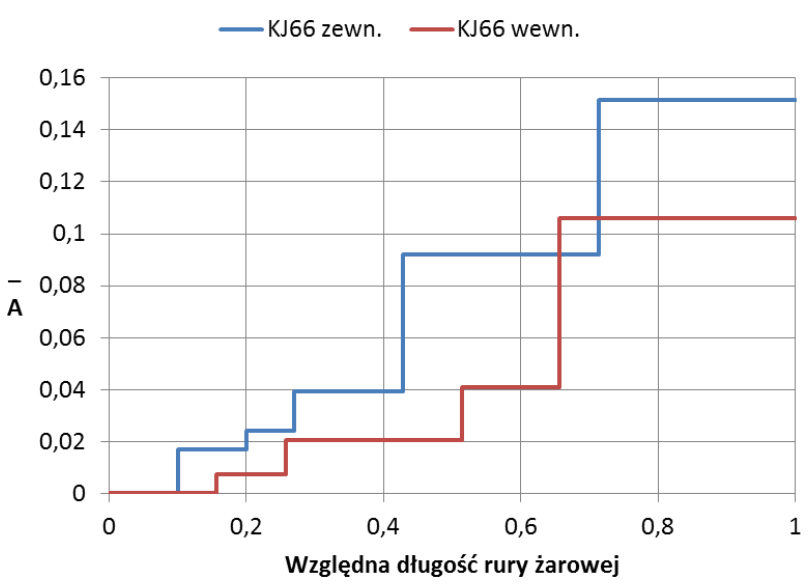

Rys. 9. Wymiary charakterystyczne dla rury żarowej KJ-66 [2,3,9]

Kolejna grupe stanowią rozwiązania komory spalania silnika GR130/180. Komora ta jest zbliżona wymiarami do komory silnika KJ-66. Stosowana jest w silnikach będących twórczym rozwinięciem rozwiazania bazowego. Silniki rodziny GR charakteryzuje 2-3 krotny wzrost siły ciagu przy zachowaniu gabarytów zewnętrznych (rys10).

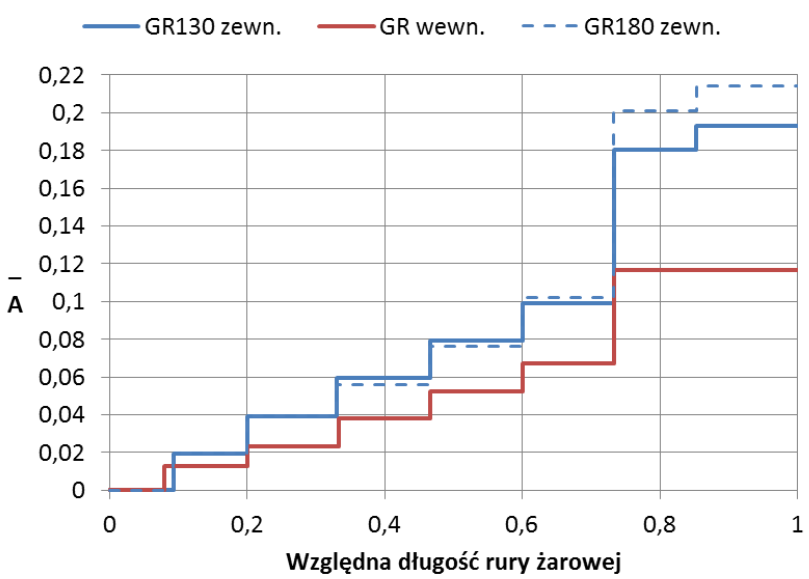

Rys. 10. Wymiary charakterystyczne dla rury żarowej silników GR130 oraz GR-180 [6,7]

Zwiększenie sily ciagu uzyskano poprzez zwiększenie masowego natężenia przepływu o 60\%. Istotnym jest że do długości 0,3 rury zachowano schemat rozwiazania (strefa wstępnego odparowania paliwa), natomiast nieznacznemu zmniejszeniu uległy otwory sekcji pośredniej, przy jednoczesnym zwiększeniu otworów sekcji chłodzącej.

\section{Podsumowanie}

Prezentowane komory spalania pochodzą od silników opartych na dwóch typach łożysk 688 o średnicy zewnętrznej bieżni 16 mm oraz łożyska typu 608 o średnicy $22 \mathrm{~mm}$. Średnica zewnętrzna determinuje wymiary pierścienia wewnętrznego komory spalania. Komorę spalania silnika KJ-66 należy uznać za rozwiązanie wzorcowe - opracowane w roku 1997. Najbardziej zwarta komora spalania charakteryzuje się silnik MW54. Komory spalania silników OH7 i TK50 to konstrukcje bliźniacze (rys.8). Komora spalania silnika TK50 powstała przez wydłużenie pierścieni rury żarowej silnika $\mathrm{OH7}$. Są one na tyle uniwersalne że pasują do łożysk 608 i $688 \mathrm{co}$ czyni przyjęty schemat uniwersalnym. Komory silników GR130 i GR180 stanowią następną generację rozwiazzań, która zastapiła komorę spalania silnika $\mathrm{KJ}-66$.
Rozpatrując dystrybucję powietrza w elementach rury żarowej warto przyjżeć się schematom charakterystycznym dla komercyjnych silników turbinowych [5]. W przypadku tych rozwiązań podaje się sumaryczny udział bez rozdzielenia na pierścienie (rys.11).

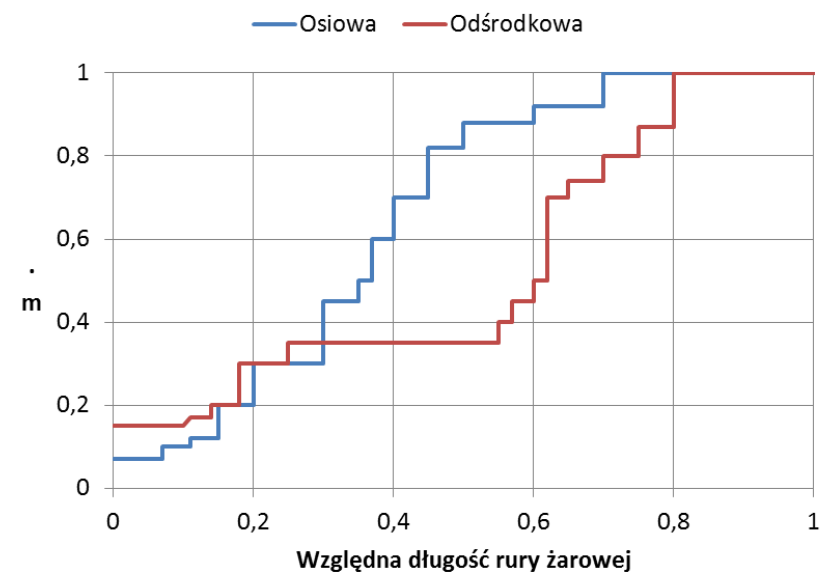

Rys. 11. Sumaryczna dystrybucja powietrza w rurze żarowej silnika turbinowego [5].

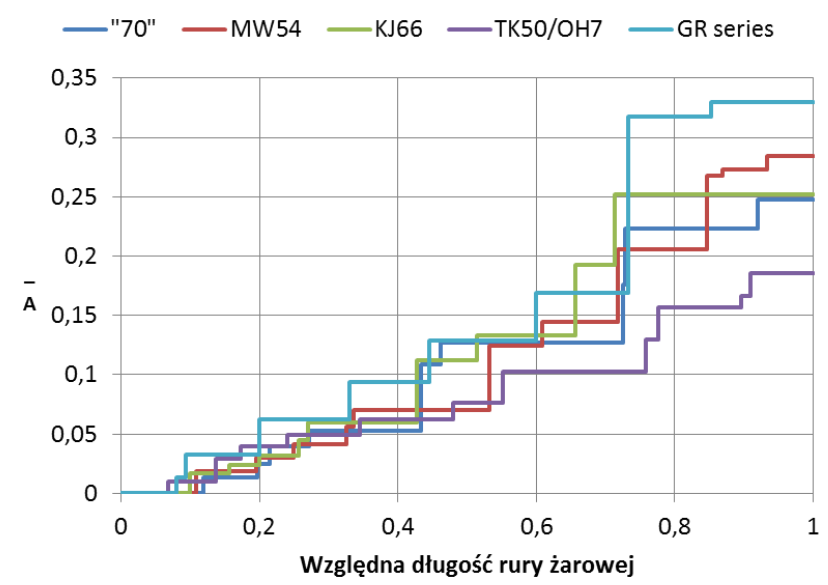

Rys. 12. Sumaryczna dystrybucja powietrza w rurze żarowej silnika turbinowego klasy mikro.

Porównując rozkłady dystrybucji powietrza w rurach żarowych, pomiędzy silnikami klasy mikro (rys. 12), a silnikami komercyjnymi o sprężarkach osiowych i promieniowych (rys.11), należy stwierdzić, że charakter krzywej jest zachowany bez wyraźnej tendencji rozgraniczającej rozwiązania w zakresie układu konstrukcyjnego sprężarki jak ma to miejsce przy pełnowymiarowych lotniczych silnikach turbinowych.

Bibliografia:

1. Czarnecki, M., Olsen, J. , Influence of selected parameters on micro gas turbine compressor design, Journal of KONES, 2017 vol. 24 p.45-52,

2. Kamps, T., Model Jet Engines, Traplet Publications, Worcestershire 2005,

3. Schreckilng, K., Home Built Model Turbines, Traplet Publications, Worcestershire 2005,

4. Schreckilng K., The model turbo-prop engine for home construction. Traplet Publications, Worcestershire 2000

5. Скубачевский Г.С.,. Авиационные газотурбинные двигатели. Конструкция и расчет деталей. Машиностроение, 1969.

6. Rutten, G.,GR130 Turbine - KJ-66 Upgrade, 1.12.2008,

7. Rutten, G.,GR180 Turbine,1.12.2008, 
8. Parish, R., Wright, J., Murphy, M., Plans for the MW54 Gas Trurbine $2^{\text {nd }}$ edition, August 2000 ,

9. Schreckling, K.,KJ-66 Design plans - 15.02.1997.

\section{Small scale gas turbine combustor sizing}

Presented article is focused on initial design of small scale combustors for micro scale jest engines. In comparison to the full size equivalent, small combustor are design and manufactured in experimental way. To try building universal numeric model for micro size design is important to acquire as many data as possible to identify boundary conditions for a model. Major advantage of analyzing different design is possibility to quick building prototype design without investigating complex process of combustion.

Keywords: gas turbine, micro scale, flame tube, distribution.

Autorzy:

dr inż. Michal Czarnecki - Politechnika Rzeszowska, Wydział Budowy Maszyn i Lotnictwa, Katedra Samolotów i Silników Lotniczych e-mail czarn@prz.edu.pl 